\title{
Flow Cytometry of Bacteria: a Promising Tool in Experimental and Clinical Microbiology
}

\author{
By ERIK BOYE, ${ }^{*}$ HARALD B. STEEN ${ }^{2}$ AND KIRSTEN SKARSTAD 2 \\ ${ }^{1}$ Department of Medical Physics, The Norwegian Radium Hospital and ${ }^{2}$ Department of \\ Biophysics, Norsk Hydro's Institute for Cancer Research, Montebello, Oslo 3, Norway
}

(Received 13 July 1982; revised 30 September 1982)

\begin{abstract}
The DNA and protein content of individual Escherichia coli cells were measured at a rate of $10^{4}$ cells per second with a sensitive microscope-based flow cytometer. DNA and protein were quantified by measuring the fluorescence from cells stained with a combination of the DNAbinding drugs Mithramycin and ethidium bromide and by scattered light, respectively. Separate experiments demonstrated that the light scatter signal was proportional to protein content. Dual parameter histograms (fluorescence/scattered light) of bacterial cultures gave detailed pictures of changes dependent upon the growth conditions and of the cell cycle kinetics. Effects of antibiotics could be readily detected and characterized after a few hours. The results demonstrate that flow cytometry is a promising method for application in experimental and clinical microbiology.
\end{abstract}

\section{INTRODUCTION}

Flow cytometry has for several years been a useful method for studying the characteristics of eukaryotic cells. By labelling cellular macromolecules (DNA, RNA or protein) with specific fluorescent dyes the single cell contents of these macromolecules can be accurately and rapidly measured. Bacterial cells have not readily lent themselves to flow cytometric experiments, mainly because of their smaller size and lower content of macromolecules. A few such studies have been reported in the literature (Bailey et al., 1977; Paau et al., 1977a, 1977b), but these experiments appear to have been hampered by non-specific binding of the fluorescent dye and limited instrumental sensitivity.

We have used a laboratory-built flow cytometer based on a standard fluorescence microscope (Steen \& Lindmo, 1979; Steen, 1980). This instrument permits accurate measurements of DNAspecific fluorescence and scattered light from individual bacterial cells at a rate of $10^{4}$ cells s-1. The two parameters may be measured simultaneously and displayed in dual parameter histograms. A preliminary report of this application of flow cytometry has been published (Steen \& Boye, 1981).

The purpose of the present report is to show that flow cytometry can be used in quantitative and qualitative studies of bacterial growth and metabolism. We present data showing that DNA-associated fluorescence from Mithramycin/ethidium bromide is a good measure of the DNA content of single Escherichia coli cells and that the amount of scattered light from individual bacteria is proportional to cellular protein content. Furthermore, it is shown that the effects of different antibiotics on bacterial growth and progression through the cell cycle can be assessed more rapidly and in more detail than is practicable with conventional methods.

\section{METHODS}

Bacterial strains and bacterial growth. The $E$. coli strains used were B/r A and the $\mathrm{K}-12$ strain W3110, which are both wild-type for DNA replication, and the K-12 strain E177 dnaA, which is temperature sensitive in initiation of

Abbreviation: FITC, fluorescein isothiocyanate. 
new rounds of DNA replication (Wechsler \& Gross, 1971). Bacteria were grown in aerated $\mathrm{K}$-glucose medium (Boye \& Krisch, 1980), the wild-types at $37^{\circ} \mathrm{C}$ and the $d$ na $A$ mutant at either $32^{\circ} \mathrm{C}$ or $42^{\circ} \mathrm{C}$.

Flow cytometry. The microscope-based flow cytometer has been described in detail elsewhere (Steen \& Lindmo, 1979; Lindmo \& Steen, 1979; Steen, 1980). In short, a nozzle with hydrodynamic focusing produced a laminar jet of water with the bacterial suspension travelling along the jet axis. The jet was directed at an oblique angle on to a microscope cover slip, where the bacterial flow remained laminar across the glass plate. The stream of cells across the cover slip passed through the focus of a fluorescence microscope with an oil immersion objective. The microscope used incident illumination from a $100 \mathrm{~W}$ mercury arc lamp, which means that the flash of fluorescent light produced by each bacterial cell was collected through the same objective. The light was detected by a photomultiplier tube which gave out an electrical pulse proportional to the light intensity of the fluorescence. The electrical pulses were sized and stored in a multi-channel pulse height analyser. The scattered light was collected by a second microscope operating in a dark field configuration and was detected by a photomultiplier tube. The output pulses from this photomultiplier were sized and stored in the same multi-channel analyser, thus yielding dual parameter histograms of bacteria with regard to their content of the fluorescent dyes and to the light scattered by them. A typical histogram contained data from about 300000 bacteria, which were measured at a rate of 2000 $\mathrm{s}^{-1}$. At this rate the coincidence of cells, i.e. the presence of two cells in the illumination field simultaneously, was less than $1 \%$.

Fixation and staining. Bacterial cultures were diluted in cold $70 \%$ aqueous ethanol and were stored in the cold overnight. Fixation times down to $10 \mathrm{~min}$ gave essentially the same histograms. The cells were washed twice by centrifugation in $0.1 \mathrm{M}$-Tris $/ \mathrm{HCl}$ buffer, $\mathrm{pH} 7 \cdot 4$, before resuspension in the same buffer containing Mithramycin $\left(50 \mu \mathrm{g} \mathrm{ml}^{-1}\right)$ and ethidium bromide $\left(25 \mu \mathrm{g} \mathrm{ml}^{-1}\right), \mathrm{MgCl}_{2}(25 \mathrm{mM})$ and $\mathrm{NaCl}(100 \mathrm{~mm})$. For protein staining, the fixed cells were washed once in $0 \cdot 1 \mathrm{M}$-phosphate buffer, $\mathrm{pH} 9 \cdot 0$, and resuspended in the same buffer. A freshly dissolved solution of fluorescein isothiocyanate (FITC) $\left(3 \mu \mathrm{g} \mathrm{ml}^{-1}\right)$ in $0 \cdot 1 \mathrm{M}$-phosphate buffer, $\mathrm{pH} 9 \cdot 0$, was added dropwise to final concentration of $1 \mu \mathrm{g} \mathrm{ml}^{-1}$. FITC was allowed to bind covalently to protein during an $8 \mathrm{~h}$ storage in the refrigerator before unbound dye was washed off by centrifugation and the cells were resuspended in $0.02 \mathrm{M}-$ phosphate buffer, $\mathrm{pH} 7 \cdot 4$, containing $0 \cdot 13 \mathrm{M}-\mathrm{NaCl}$.

Chemicals. The antibiotics used were chloramphenicol from Sigma, erythromycin (Abboticin) from Abbot Labs, streptomycin from Nova, and doxycycline (Vibramycin) from Pfizer. Mithramycin was from Pfizer, ethidium bromide from Calbiochem, FITC from Bio Mérieux, and benzylpenicillin from Apothekernes Laboratorium, Oslo, Norway.

\section{RESULTS}

In our flow cytometric analyses of $E$. coli, two parameters were simultaneously measured in individual bacterial cells: DNA-associated fluorescence and scattered light. An example of a two-dimensional histogram is shown in Fig. 1(a). During rapid growth E. coli cells displayed a wide variation in DNA-associated fluorescence and in scattered light, which reflected the continuous and asynchronous DNA replication occurring in such cultures (Fig. 1a). The linear ridge of the histogram indicated that the DNA-associated fluorescence and scattered light were proportional, showing that larger cells had more DNA. The variation in fluorescence at a given light scatter value corresponded to a coefficient of variation between 11 and $15 \%$, whereas the coefficient of variation in scattered light at a given value of fluorescence intensity was between 11 and $14 \%$. The instrumental coefficient of variation was below $1 \%$ (Steen \& Lindmo, 1979) and the variability observed was therefore mainly biological.

\section{Fluorescence measurements of DNA content}

The fluorescence of mammalian cells stained by Mithramycin and ethidium bromide is closely proportional to their DNA contents (Ward et al., 1965; Barlogie et al., 1976). We found that this was also true for bacterial cells. The bacteria could be manipulated by different methods to contain only integers of fully replicated chromosomes. First, when a dnaA mutant was grown at $42{ }^{\circ} \mathrm{C}$ it could no longer initiate new rounds of DNA replication, but still maintained its ability to divide (Wechsler \& Gross, 1971). Thus, after prolonged growth these bacteria had one full chromosome per cell, as could be clearly demonstrated by flow cytometry (Steen \& Boye, 1980). Secondly, when the bacteria were grown in the presence of an inhibitor of protein synthesis, two cell cycle events were blocked: cell division and initiation of DNA replication. However, active replication forks continued to the terminus, and such drugs therefore made the cells stop DNA replication with an integral number of fully replicated 


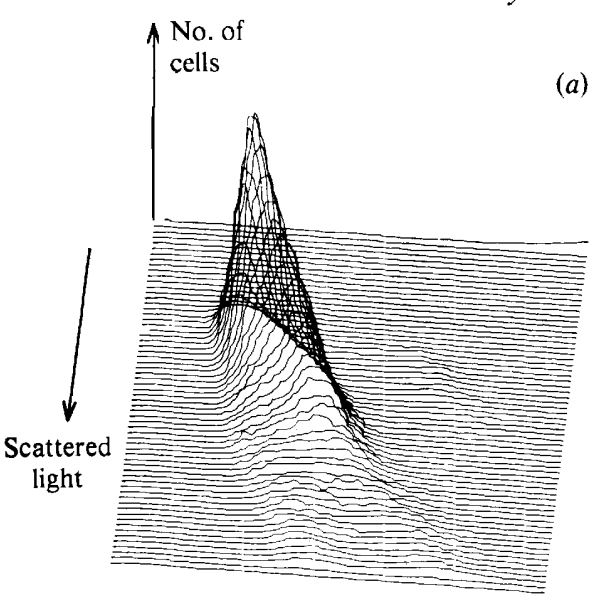

DNA

(a)

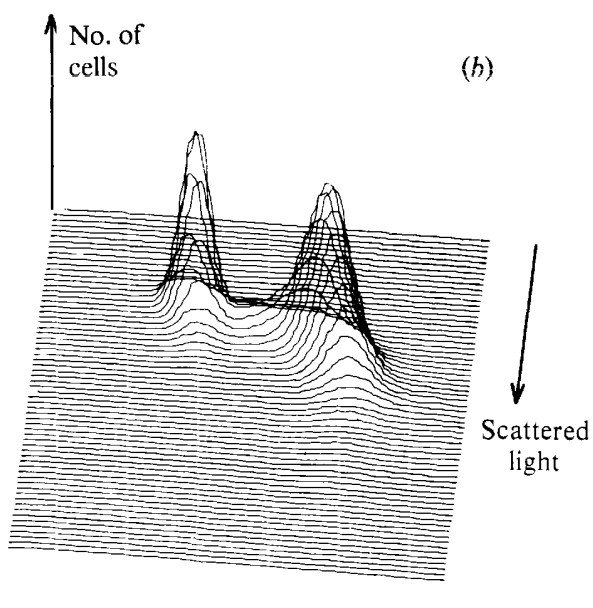

DNA

Fig. 1. Histograms of a culture of $E$. coli K-12 strain W3110 grown in aerated K-glucose medium at $37^{\circ} \mathrm{C}$. The cells were grown exponentially to a concentration of about $5 \times 10^{7} \mathrm{ml}^{-1}(a)$ before chloramphenicol $\left(100 \mu \mathrm{g} \mathrm{ml}^{-1}\right)$ was added and incubation continued for $4 \mathrm{~h}(b)$. Each cell gave rise to two independent pulses of light on passing through the microscope focus, one pulse of DNA-associated fluorescence and one pulse of scattered light, thereby adding one event in one of the elements on the $63 \times 63$ element data-storage matrix. The channel number of this event, i.e. the position in the twodimensional histogram, is proportional to the intensities of the fluorescent light and of the scattered light. Each panel is a graphical representation of the content of the memory matrix.

chromosomes. An example of cells grown in the presence of chloramphenicol is shown in Fig. $1(b)$. The peak of cells with lowest DNA content represents cells that have replicated one chromosome to two full chromosomes. The other peak represents cells that have replicated two chromosomes to give four full chromosomes. Thirdly, the growth of E. coli could be followed into stationary phase. The majority of bacteria in stationary phase do not replicate their DNA and are expected to contain only one full chromosome per cell.

These three treatments of the bacteria should give integer numbers of fully replicated chromosomes, thus allowing comparison of the fluorescence signals with known DNA contents. The results showed that the fluorescence values obtained were in simple integral proportions. For example, the one-chromosome peak of the dnaA mutant had a DNA fluorescence equal to exactly one-half and one-fourth of the fluorescence from the two peaks found after chloramphenicol treatment, representing two and four chromosomes, respectively (Fig. $1 b$ ). Thus, we concluded that fluorescence from Mithramycin/ethidium bromide was a good quantitative measure of the DNA contents of individual bacterial cells.

Our experiments with stationary phase cells gave some unexpected results. Bacteria in rapid exponential growth (containing on the average three chromosome equivalents per cell) entering into stationary phase occurred in a narrow peak representing two full chromosomes per cell. When the bacterial titre no longer increased, virtually all the bacteria contained two full chromosomes. However, after continued incubation at $37^{\circ} \mathrm{C}$ overnight, a sizeable fraction of the bacteria had divided so that a distinctive one-chromosome peak appeared (data not shown).

\section{Scattered-light measurements of cell protein}

The other parameter displayed in our two-dimensional histograms was scattered light. By staining ethanol-fixed cells with the protein-specific dye FITC, protein-associated fluorescence and scattered light can be measured simultaneously. Such experiments performed with mammalian cells showed a close proportionality between the two parameters (Steen, 1980). FITC fluorescence has also been shown to be proportional to the total protein content of mammalian cells (Lindmo, 1981). We have stained bacterial cells with FITC and measured FITC fluorescence and scattered light in the dual parameter mode. The results showed that the two parameters were proportional over a large range of values (Fig. 2). The coefficients of 


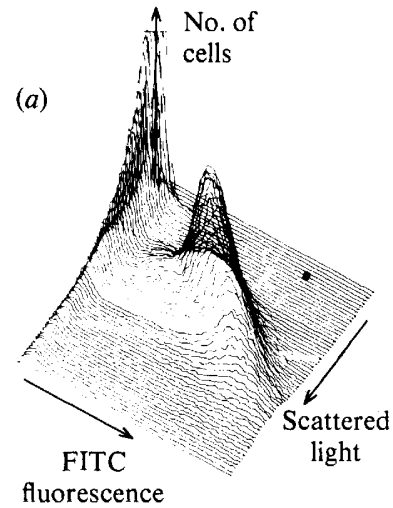

fluorescence

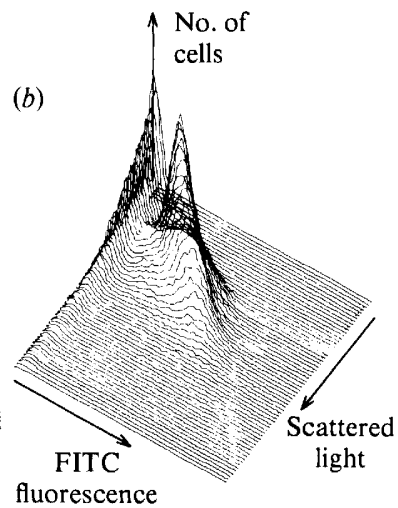

fluorescence

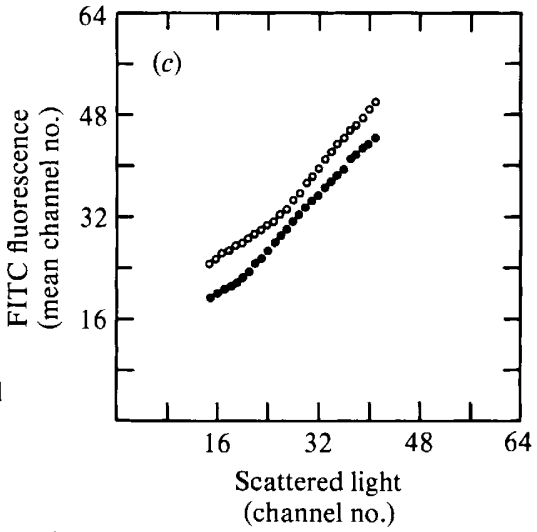

(channel no.)

Fig. 2. Correlation between protein-associated fluorescence and scattered light. Cells of strain W3110 were grown to $5 \times 10^{7} \mathrm{ml}^{-1}$ before chloramphenicol $\left(100 \mu \mathrm{g} \mathrm{ml}^{-1}\right)$ was added. Samples were taken after $0 \mathrm{~h}(a)$ and $4 \mathrm{~h}(b)$ of continued incubation; $(c)$ shows the correlation between fluorescence and light scattering in the data from $(a)(O)$ and $(b)(O)$. The arithmetic mean of fluorescence values (measured as channel number in the multi-channel analyser) is shown for each channel along the light scatter axis. The peaks (representing signal noise) seen close to the origins in $(a)$ and $(b)$ have been excluded when calculating the data of $(c)$.

variation in the values of scattered light and of FITC fluorescence (for a fixed value of the other parameter) both for exponentially growing cells and for chloramphenicol-treated cells were in the range $12-14 \%$. The FITC/light scatter plots for exponentially growing and chloramphenicol-treated bacteria do not fall along the same line (Fig. $2 c$ ). This may indicate a difference in FITC staining, but the actual reason is not known.

In an attempt to relate scattered light to more common measures of cell size and protein content, the following experiment was performed. An exponentially growing culture of strain W3110 was exposed to $50 \mu \mathrm{g}$ chloramphenicol ml $\mathrm{m}^{-1}$ and growth was continued at $37^{\circ} \mathrm{C}$ for $4 \mathrm{~h}$. Samples were removed at regular intervals for determination of average values of protein content or cell size by three different methods: (i) mean cell size in the population was determined in a Coulter Counter fitted with a $30 \mu \mathrm{m}$ orifice (kindly supplied by $\mathbf{H}$. E. Kubitschek, Argonne National Laboratory); (ii) protein content was measured with the established Coomassie blue method (Bradford, 1976), and protein content per cell was calculated from the cell concentration obtained with the Coulter counter; (iii) scattered light per bacterium was measured by flow cytometry. The results showed that the three parameters were very well correlated (Fig. 3). Although the range of values of the three parameters was relatively small in this experiment, it may be noted that large variations in the cellular contents of DNA and RNA and in cell shape could be observed during chloramphenicol treatment. These parameters, therefore, had little influence on the light scatter signal. We conclude that scattered light is a good measure of protein content of individual $E$. coli cells.

\section{Detection of the effect of antibiotics}

The effect of different antibiotics was studied to demonstrate the power and possibilities of the present method. The histogram of chloramphenicol-treated cells (Fig. $1 b$ ) exhibited two prominent peaks representing cells with two and four fully replicated chromosomes. Streptomycin and erythromycin, which are also protein synthesis inhibitors, gave similar results (data not shown). However, higher concentrations of erythromycin had to be used to achieve comparable effects, in accordance with the higher MIC of this drug. The effect of the different drugs on cell multiplication is shown in Fig. 4; in no case could the changes in the histograms be ascribed to entrance into the stationary phase of growth. The tetracycline doxycycline is also a protein synthesis inhibitor, but its effect on the cell cycle of $E$. coli was qualitatively different from that described above (Fig. 5a). There was no significant change in the histogram even after 


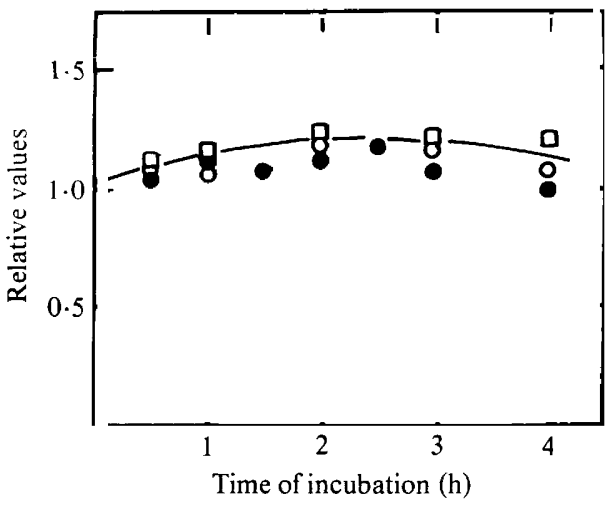

Fig. 3

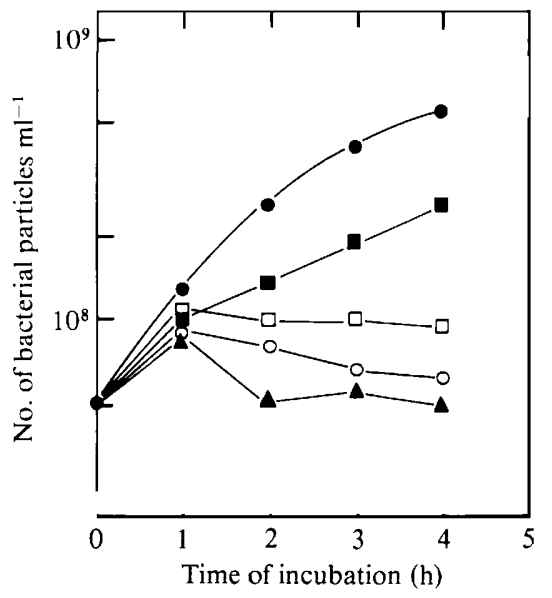

Fig. 4

Fig. 3. Comparison of different methods to measure cell size or protein contents of $E$. coli cells. A culture of strain W3110 was exposed to chloramphenicol $\left(50 \mu \mathrm{g} \mathrm{ml}^{-1}\right)$ for different periods of time. Average cell size was measured with a Coulter counter $(O)$; average protein content per cell was measured with the Coomassie blue method after extensive washing of the cells $(\square)$ and with light scattering in the flow cytometer $(0)$.

Fig. 4. Effect of antibiotics on the multiplication of strain W3110. An exponentially growing culture was exposed to no drug $(\boldsymbol{O})$ or chloramphenicol $(\square)$, doxycycline $(\boldsymbol{\Delta})$, streptomycin $(\bigcirc)$, or erythromycin $(\square)$ each at $100 \mu \mathrm{g} \mathrm{ml}^{-1}$. Cell concentration was measured with a Coulter counter.
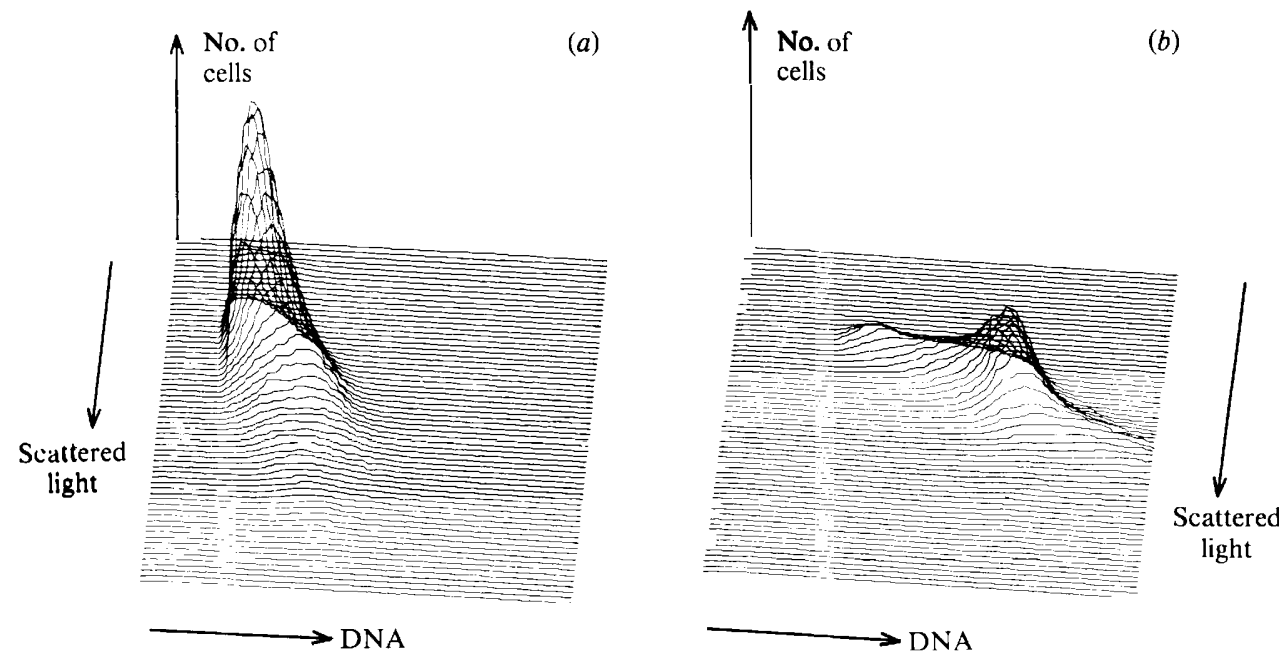

Fig. 5. Effect of doxycycline on cell cycle progression. Cells of strain W3110 were grown to $5 \times$ $10^{7} \mathrm{ml}^{-1}$ (shown in Fig. $1 \mathrm{a}$ ) before doxycycline was added. The cells were grown for $4 \mathrm{~h}$ in the presence of doxycycline at $100 \mu \mathrm{g} \mathrm{ml}^{-1}(a)$ or $10 \mu \mathrm{g} \mathrm{ml}^{-1}(b)$.

$4 \mathrm{~h}$ of growth at a concentration of $100 \mu \mathrm{g} \mathrm{ml}^{-1}$, but cell multiplication ceased completely (Fig. 4). Thus, both DNA replication and cell division were stopped immediately by this concentration of doxycycline. This was in contrast to the other drugs which allowed active replication forks to continue to the terminus. It may be that doxycycline has a direct effect upon the progression of the replication fork. It is interesting to note that cells treated with chloramphenicol, streptomycin or erythromycin all resumed DNA replication when the drugs were removed, and the cell concentration and viable titre increased. With doxycycline, however, DNA replication was permanently blocked and no viable cells could be detected even after short 

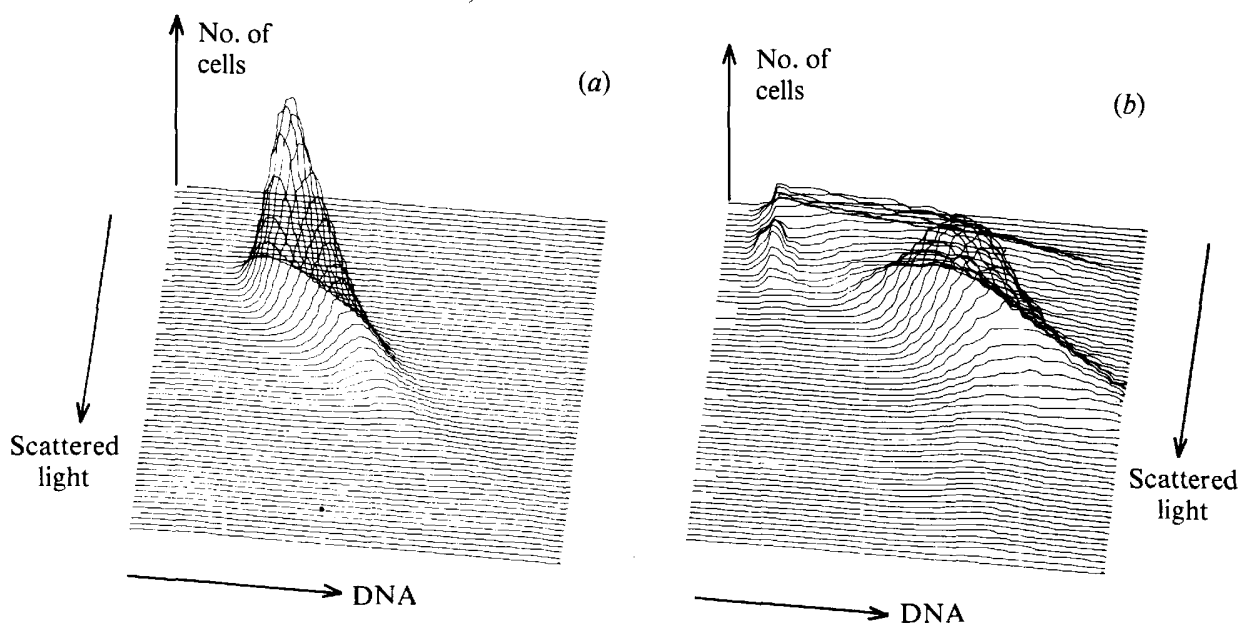

Fig. 6. Histograms of a culture of strain W 3110 grown exponentially to about $5 \times 10^{7}$ cells $\mathrm{ml}^{-1}(a)$ before penicillin $\left(5 \mu \mathrm{g} \mathrm{ml}^{-1}\right)$ was added and incubation was continued for $1 \mathrm{~h}(b)$.
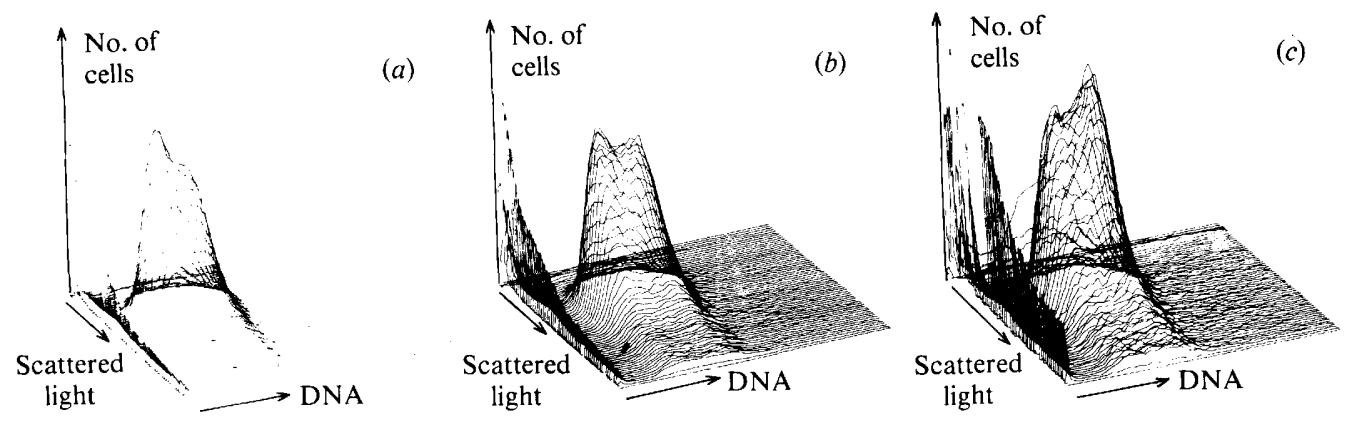

Fig. 7. Histograms of exponentially growing cells of strain W3110. The bacteria were grown in a medium with a basic composition equal to $\mathrm{K}$-glucose medium except that Casamino acids and glucose were replaced with alanine $\left(5 \mathrm{mg} \mathrm{ml}^{-1}\right)$ and proline $\left(5 \mathrm{mg} \mathrm{ml}^{-1}\right)$. Cell generation time was $70 \mathrm{~min}$. Samples were taken at concentrations of $8.5 \times 10^{6}(a), 2.5 \times 10^{7}(b)$, and $1.4 \times 10^{8}$ bacteria $\mathrm{ml}^{-1}(\mathrm{c})$.

exposures to the drug. A lower concentration of doxycycline, $10 \mu \mathrm{g} \mathrm{ml}^{-1}$, (Fig. $5 b$ ) had an effect similar to that shown for chloramphenicol in Fig. 1, except that in the presence of doxycycline most of the cells halted with four full chromosomes, indicating that cell division was inhibited more effectively than initiation of DNA replication.

Penicillins affect the cell wall synthesis of E. coli, and the filamentous growth caused by the drug can easily be seen with a microscope. Flow cytometry can reveal such changes after exposure to penicillin. Figure 6 shows how the cells of an exponentially growing culture $(a)$ dramatically increased their DNA content during a $1 \mathrm{~h}$ exposure to $5 \mu \mathrm{g}$ benzylpenicillin $\mathrm{ml}^{-1}$ (b).

\section{Variability in exponentially growing cultures}

When experiments were repeated, we never obtained exactly the same DNA/light scatter histograms even though the external variables were carefully controlled. To examine this variability, strain W3110 was grown from a concentration of $10^{4}-10^{8}$ bacteria $\mathrm{ml}^{-1}$ with a doubling time of $70 \mathrm{~min}$. Frequent samples were taken for flow cytometry and for assay of cell concentration (viable titre on agar plates). Although the growth was strictly exponential over these four decades of concentration (data not shown), flow cytometry revealed that the culture was not constant with respect to the distribution of cellular DNA content (Fig. 7). The DNAfluorescence profile clearly shifted to higher values as the cell concentration increased. 
Apparently, balanced growth had not been obtained. Our experience with both batch cultures and chemostat cultures has been that even when the externally controllable parameters (temperature, cell concentration, aeration) were controlled carefully and reproduced from experiment to experiment, the histograms could show significant variations.

\section{DISCUSSION}

Flow cytometry has provided a valuable body of information about eukaryotic cells, particularly in the field of cell cycle kinetics. The results presented here demonstrate that the method may have a corresponding potential in studies of bacterial growth and metabolism. With the present microscope-based flow cytometer the DNA and protein content of individual bacterial cells can be accurately measured.

When bacteria are exposed to inhibitors of protein synthesis, both DNA replication and cell division are affected. The examples shown for $E$. coli demonstrate how easily and how early the effects of protein synthesis inhibitors can be detected by flow cytometry. This is also true for other drugs affecting DNA content or cell size, as exemplified by penicillin (Fig. 6). Thus, flow cytometry may find an application in the management of clinical infections, where an early indication of drug sensitivity could be of vital importance. It should also be possible to identify the micro-organisms present in clinical infectious fluid by the present technique, particularly when fluorescent antibodies to different bacteria become available.

Current methods of measuring the DNA or protein contents of bacteria give mean values for the entire cell population. One way to measure parameters representative of a specific stage in the cell cycle is to synchronize the bacteria. It is not easy to obtain a fully synchronized bacterial culture, and all current synchronization techniques introduce perturbations into the normal cell cycle. With flow cytometry, cell parameters for individual bacteria can be obtained during unperturbed, balanced growth. Hence, studies of the bacterial cell cycle should be greatly simplified. The replication of a chromosome is readily detected as an increase of the DNA content. When $E$. coli cells grow slowly, they contain between one and two full chromosomes. Newborn cells have one chromosome, old cells have two chromosomes while preparing for division. Knowing the cell doubling time in such a culture, the duration of DNA synthesis may be estimated from DNA histograms by the fraction of cells having between one and two chromosomes. Such investigations with batch cultures and continuous cultures are being performed, and the results will be published elsewhere.

This work was supported by the Norwegian Cancer Society (Landsforeningen mot Kreft).

\section{REFERENCES}

Bailey, J. E., FAzel-Madjlessi, J., McQuitty, D. N., Lee, L. Y., Allred, J. C. \& Oro, J. A. (1977). Characterization of bacterial growth by means of flow microfluorometry. Science 198, 1175-1176.

Barlogie, B., Spitzer, G., Hart, J. S., Johnston, D. A., Büchner, T., SchmanN, J. \& Drewinko, B. (1976). DNA histograms of human hemopoietic cells. Blood 48, 245-258.

BOYE, E. \& KRISCH, R. E. (1980). Induction and repair of DNA double-strand breaks in bacteriophage lambda superinfecting E. coli. International Journal of Radiation Biology 37, 119-133.

BRADFORD, M. M. (1976). A rapid and sensitive method for the quantitation of microgram quantities of protein utilizing the principle of protein-dye binding. Analytical Biochemistry 72, 248-254.

Lindmo, T. (1981). Protein synthesis as a function of protein content in exponentially growing NHIK 3025 cells studied by flow cytometry and cell sorting. Experimental Cell Research 133, 237-245.
Lindmo, T. \& SteEn, H. B. (1979). Characteristics of a simple, high-resolution flow cytometer based on a new flow configuration. Biophysical Journal 28, 3344.

PaAu, A. S., Lee, D. \& Cowles, J. R. (1977a). Comparison of nucleic acid content in free-living and symbiotic Rhizobium meliloti by flow microfluorometry. Journal of Bacteriology 129, 11561158.

PaAu, A. S., Cowles, J. R. \& Oro, J. A. (1977b). Flow microfluorometric analyses of Escherichia coli, Rhizobium meliloti, and Rhizobium japonicum in different stages in the growth cycle. Canadian Journal of Microbiology 23, 1165-1169.

SteEN, H. B. (1980). Further developments of a microscope-based flow cytometer: light scatter detection and excitation intensity compensation. Cytometry 1, 26-31.

Steen, H. B. \& Boye, E. (1980). Bacterial growth studied by flow cytometry. Cytometry 1, 32--36. 
STEEN, H. B. \& BoYE, E. (1981). Escherichia coli growth studied by dual-parameter flow cytophotometry. Journal of Bacteriology 145, 1091-1094.

STEEN, H. B. \& Lindmo, T. (1979). Flow cytometry: a high resolution instrument for everyone. Science 204, 403-404.
WARD, D. C., ReICH, E. \& GoldberG, I. H. (1965). Base specificity in the interaction of polynucleotides with antibiotic drugs. Science 149, 1259-1263.

WECHSLER, J. A. \& GROSS, J. D. (1971). Escherichia coli mutants temperature-sensitive for DNA synthesis. Molecular and General Genetics 113, 273-284. 